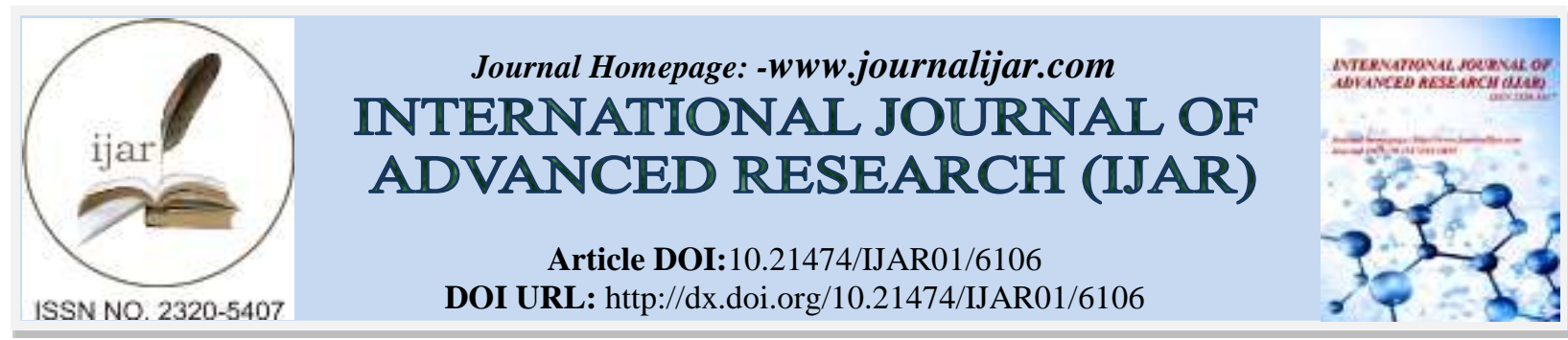

RESEARCH ARTICLE

\title{
ACCOUNTABILITY AND CREDIBILITY OFNON GOVERMENTAL ORGANISATION (NGO'S).
}

\author{
Mr. Antony Joseph Prabakar ${ }^{1}$ and Dr. T. Giftson ${ }^{2}$.
}

1. Ph.D Scholar, Department of Social Work, Bishop Heber College, Thiruchirapalli.

2. Assistant Professor of Social Work Bishop Heber College, Thiruchirapalli.

\section{Manuscript Info}

Manuscript History

Received: 19 October 2017

Final Accepted: 20 November 2017

Published: December 2017

Key words:-

Accountable, governance, efficient.

\begin{abstract}
When one gets the idea of starting an NGO? The spark when they see an opportunity for improvement in their society; the motivation is not to attract funds or showcase their contribution. It is driven by an inherent belief about the circumstances in which people need to live in - a life of respect in a healthy surrounding in a sustainable environment. When social visionaries see that opportunity to create a positive social change, they step out of their comfort zone, get likeminded people around them and begin the journey. As NGOs have a prominent role in the development of society, they are scrutinized and pressure to demonstrate their resources in an efficient, accountable and transparent manner. Their legitimacy in managing to resources is closely tied to their credibility and accountability to their donors and the public at large, their adherence to their mission, the transparency of their processes, and their effectiveness in fulfilling their mandate. The study will facilitate the current scenario on their systems, process, programme implementation, governance, and to demonstrate that NGO's are credible and they are accountable.
\end{abstract}

Copy Right, IJAR, 2017,. All rights reserved.

\section{Introduction:-}

NGOs fulfill a number of functions in areas which tend to be neglected by the private and public sectors. Due to declining public sector / governmental provision of services, NGOs have played an increasingly influential role in a variety of activities which impact upon the lives of many people. Accountability calls for a simplified structure that avoids duplication and achieves greater impact; empowered and responsible staff managers; a leaner and more efficient non-governmental organization (NGO) that fosters management excellence and is accountable for achieving results. Accountability requires that an NGO provides a professional or financial account (or justification) of it activities to another stakeholder group or individual. It presupposes that the NGO has a clear policy on who is accountable to who and for what. It involves the expectation that the NGO will be willing to accept advice or criticism and to modify its practices in the light of that advice and criticism.

Accountability has three dimensions - Transparency, Performance and Legitimacy. All these are of high significance in view of their responsibilities to donors, sponsors, programme beneficiaries, staff, state and the public. In fact, they are considered to be of even greater importance to them than to commercial undertakings. Transparency establishes trust amongst the people an NGO works with. It makes it easier for them to collaborate with the NGO, as they understand it works better and how it can best contribute to other efforts. Greater clarity in reporting and resource 
utilization enables operations to be better aligned to the goals of funders and beneficiaries equally. NGOs have today realized that they do have a responsibility of their performance to donors and the public. It is no longer acceptable simply to report in terms of program outputs.

They had to constantly work with an outcome focus and think long-term impact. The practice of social audit has also been actively explored by several NGOs. Today, many NGOs adopt strategic planning and logical framework analysis that enable them to set specific objectives across their organization and account for them. Transparency and a focus on performance will certainly pave the way for the third dimension of accountability - legitimacy. The concept of legitimacy historically came to the fore as a reaction against NGOs who have been claiming to represent groups of people and talk on their behalf.

As NGO involvement in society grew, it became a natural extension for them to advocate or campaign on behalf of groups with whom they worked. Donors also started to question the right of NGOs to speak on behalf of others questioning the basis from which they argued their advocacy stories. Therefore it has become imperative for NGOs to establish where their legitimacy comes from, and how transparent they are about their use of resources, decision making, and reporting of successes and failures.

It is therefore crucial that all laws, policies, rules and regulations relating to NGOs must categorically safeguard their autonomy, while simultaneously ensuring their accountability. NGOs are critical stakeholders in the development process and have the legitimate right to operate freely in a democratic framework. But water-tight government regulations could also lead to discouraging new NGOs to come up and instil doubts in the minds of donors about the credibility of the sector. In the new emerging paradigm in India, NGOs are seen as catalysts of policy innovation and social capital; as integrating the governmental and market institutions, playing the role of standing on behalf of the welfare of the poor and the marginalized; and as a builder of vibrant and diverse civil societies.

It is thus imperative to critically analyse the challenges faced by the sector. As the system evolves it will be highly beneficial in the Indian context to refer to global benchmarks and guidelines as mentioned above and adapt it to our local realities.

Transparency and accountability of NGOs always poses a great challenge because of the extreme diversity in terms of volume as well as nature of activities between the NGOs. One can find millions of small NGOs having total income within INR 2,00,000 to 3,00,000 per annum. At the same time, one can also find NGOs handling in excess of 1000 million rupees per year. Therefore, NGOs vary from tiny to mega NGOs.

In terms of the nature of activity, also NGOs function between radical extremes.

Few instances of activities are as under:-

1. having relief activities with tangible deliverables as the one working immediately after a natural calamity such as flood, cyclone, earthquake, etc.;

2. having a rehabilitative mission such as the NPOs who work for the rehabilitation \& reconstruction after calamities \& unfortunate happenings;

3. focusing on awareness and capacity building of people without having any tangible deliverable component;

4. Engaged in vocational training and employment generation programmes;

5. Engaged in counselling and psychological support;

6. Working as networks of smaller NPOs to mobilize people across the country/state for their rights and wellbeing;

Principles of Accountability:-

1. Key principle is that responsibility and authority has to be clearly specified, hence the person has a strong way to deliver their responsibility.

2. Providing guidance and support to the responsible person, mentoring and handholding the person in the right and to be accountable for his / her responsibility.

3. Regular monitoring and assessment of the responsibility and authority will enable the organization accountability. 


\section{Basic requirement of Accountability:-}

1. Formal registration of the organization

2. Having clear and specific vision and mission

3. Practices good governance, systems and policies

4. Programme and Operation are implemented efficiently and effectively

5. Accountable and transparent to the community and other stake holders.

\section{Conclusion:-}

As mentioned earlier, a NGO who follows the dimensions of Transparency, Performance and Legitimacy will be a model organization with high significance in their responsibilities to donors, sponsors, beneficiaries, staff, state and the public.

\section{References:-}

1. http://www.gdrc.org/ngo/accountability/

2. http://thecsrjournal.in/establishing-accountability-for-ngos/

3. NGO Accountability in the Indian Context A note by PushpaAman Singh, CEO, GuideStar India, Dec 2009.

4. NGO Accountability: Rights and Responsibilities, Julian Lee Programme on NGOs and Civil Society CASIN Geneva, Switzerland October 19, 2004.

5. https://www.intrac.org/. 